\title{
The Practice of Project-driven Teaching Mode of the Flipped Classroom: In the Design and Application of Database as an Example
}

\author{
YingLong $\mathrm{Ge}^{1 \text {, a * }}$ \\ ${ }^{1}$ School of Information Engineering, Hangzhou Dianzi University, Hangzhou Zhejiang 310012 P.R \\ China \\ ageyl@hdu.edu.cn
}

Keywords: Flipped classroom; Project-driven; Database; Teaching mode; Micro video

\begin{abstract}
Flipped classroom" have established a "student-centered" teaching mode. The teaching mode which would be applied to the "Design and Application of Database" course based on the existing "project-driven", merged with the "flipped classroom". The model is mainly with the syllabus and Project case, complemented by the teaching element such as micro-video, online exercises, online answer, and mobile electronics homework. The implementation of the teaching model to stimulate the students' learning autonomy and improve the efficiency of learning, which provide a reference implementation for other courses applied with "Flipped classroom" teaching mode.
\end{abstract}

\section{Introduction}

In the traditional classroom teaching system, the teacher is always the main body, the teaching resources are all around the body, class time, the progress of teaching and examinations are arranged by the teacher, students learn everything passively, and the learning activities is confined to the classroom and books. The personality of students cannot be effectively presented. The students with different levels needs a set of suitable for their own learning, however, the traditional way is difficult to do this, just like "differ from man to man" and "teach students in accordance with their aptitude". Therefore, the "student centered" teaching mode has become the focus of the reform of the classroom teaching model, many educators spare no effort to study and try new teaching methods.

With the development of educational information technology, the open educational technology breakthrough in the development of time and space, geographical restrictions, classroom space is extended to the network which covered any scope. Especially in 2007, America Colorado Woodland Park high school chemistry teachers Jonathan Bergmann and Aaron Sams using the "flipped classroom" [1] teaching mode, and in February 2013. The National University of Singapore, in cooperation with the American Coursera Inc has built a large open online course platform, namely MOOC (massive open online courses) [2] can greatly improve the students' learning freedom. In the novel teaching mode, students can freely choose the course according to their own plans in different time. Students can also access stored the teaching content on the remote servers, view the courseware, complete the electronic homework and exam online. Therefore students become the main part in the teaching activities, the center of teaching is no longer the teachers' "teaching", but the students "learning". The teaching mode of the "flipped classroom" is not the accumulation of the curriculum video simply, but the organic integration of body, including micro video, electronic courseware and online examination based on the learning key points.

\section{The Introduction of the Design and Application of Database Course and the Analysis of the Current Teaching Model}

Database has been widely applied in the enterprise management information system, the related curriculum not only requires understanding of database theory knowledge, and more emphasis on 
practical skills to master. This course "the Design and Application of Database" is designed to make students understand the modern database knowledge and master the database application and modeling of mainstream database system, based on the basic principle and the use of database.

The course is divided into three parts, the first part focuses on database basic theory knowledge, students are required to master the basic concept of database, relational database theory, creating and application of SQL statements, etc.; The second part is the introduction of a typical database management system, involves how to manage the database system, including database creation, backup and restore, daily maintenance, etc.; The third section is based on a typical management information system's case, involves the database in the application system architecture, database design, the designing of the stored procedure, etc.

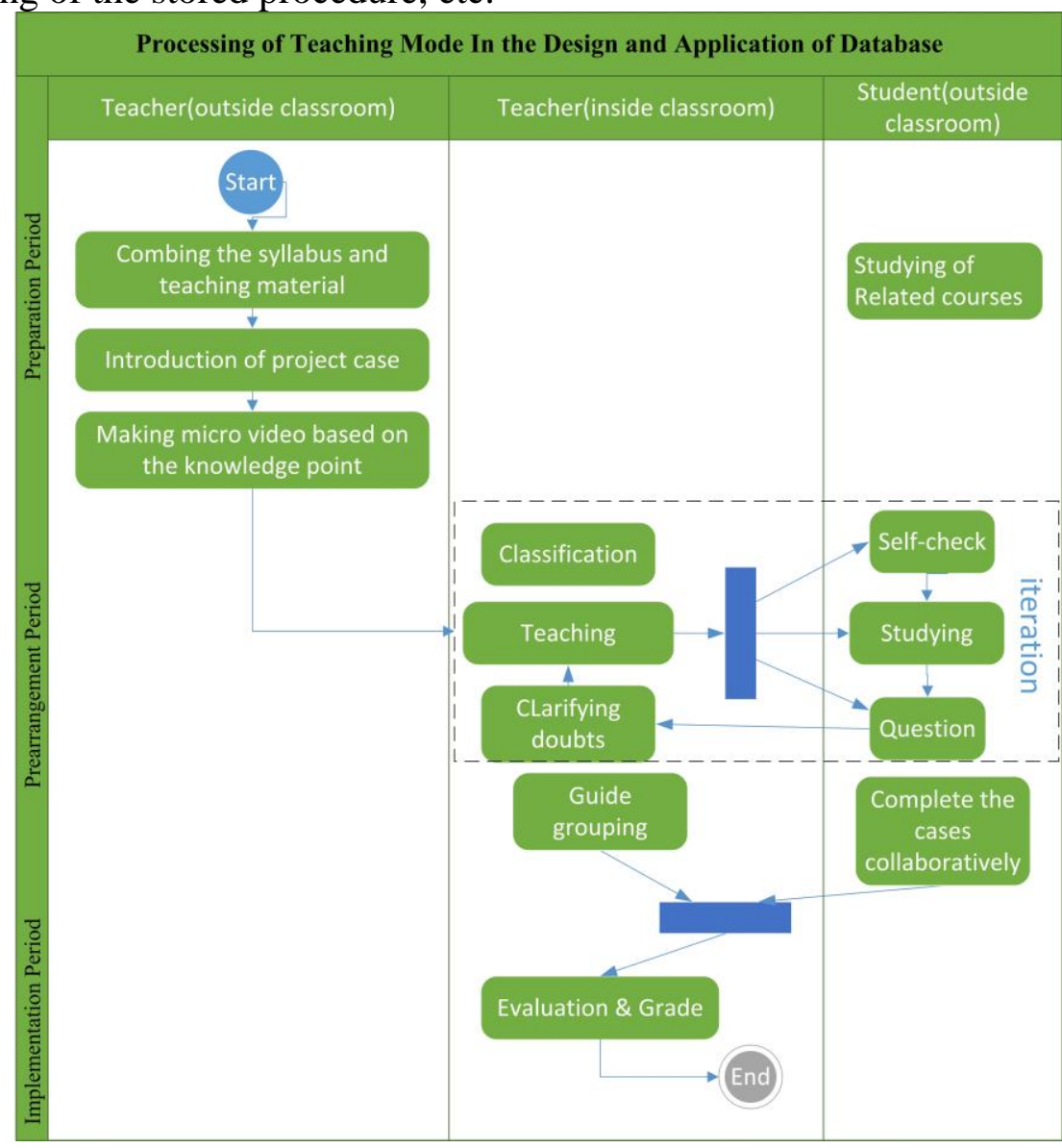

Figure. 1 The database application and the design of teaching process

In the course of the existing teaching mode, the project driven teaching mode had been adopted by ZhanJin in "database technology" course [3], the mode was introduced into the practical teaching system structure. Student groups to complete the project which is guided and supervised by teachers, the process of preliminary established the student-centered teaching structure. A heuristic project-drive case teaching mode is applied to the "advanced database technology" [4] in the course of teaching by Fen shaojin, help students to master the theory of modern mainstream database technology, improve the development of database application and practical ability, shorten the gap between the students ability in practice and the social demand, enhance the competitiveness of their employment. Li Yanling is presented the knowledge system and curriculum thinking framework of database course based on the calculation thinking of cultivating the ability, which guide the teaching process from "knowledge internalization" as the core, focus on the cultivation of students' thinking training [5]. These excellent teaching patterns is all about the student-centered. This paper build a project-driven of the flipped classroom teaching mode in the database application and the design course and implement assisted learning software platform based on above study. 


\section{The Implementation process of Project-driven Teaching Mode of the Flipped Classroom}

The project-driven of the flipped classroom teaching mode can be divided into the preparation period, prearrangement period, and implementation period according to the teaching process, as shown in figure 1. The following will describe how the "project-driven of the flipped classroom" teaching mode been implemented in the course of "design and application of database" from three periods.

Preparation Period. At this stage, teachers should sort out the syllabus of the "Design and Application of Database" course, arrange the knowledge points of course according to the relationship among the chapter section and point of the teaching content. In addition to the importance and difficulty of the description, as well as the composition of the details, which should be present different content by different types. The composition of the details lists the learning content and self-test exercises should be master for the knowledge range. For the knowledge point, the details list the points of knowledge mastery of the content to learn, this stage requires each knowledge point is divided into many key points of knowledge, each key point can take 5 8 minutes to explain, the structure as shown in table 1 .

After finishing the syllabus combing, the teacher should design the project case as a main line of curriculum content. The case of the course can be a database designing of management information system and modeling solution. The case's content includes system business analysis, database logic design and physical database design, create a table, DML statements application, backup reduction and optimization, etc. Designing many specific questions based on the combination of the content of the case and knowledge points. Through such "questions" attract students to thinking about the solution, and learn the knowledge point to solve the problem.

Table 1 The combing table of the syllabus on the "Design and Application of Database"

\begin{tabular}{|c|c|c|c|c|c|c|}
\hline \multirow{7}{*}{$\begin{array}{l}\text { The } \\
\text { Summary of } \\
\text { Knowledge } \\
\text { Points on } \\
\text { Database } \\
\text { application }\end{array}$} & No & Describe & Type & Importance & Difficulty & Detail \\
\hline & 2.1 & Backup & range & & & self-test exercises \\
\hline & 2.1 .1 & $\begin{array}{l}\text { The } \\
\text { Concept of } \\
\text { Backup, } \\
\text { Classificat } \\
\text { ion and } \\
\text { Methods }\end{array}$ & point & master & easy & $\begin{array}{l}\text { Courseware; } \\
\text { micro video: the concept of } \\
\text { backup,Classification and } \\
\text { Strategy }\end{array}$ \\
\hline & 2.1 .2 & $\begin{array}{l}\text { Logical } \\
\text { Backup }\end{array}$ & point & master & middle & $\begin{array}{l}\text { Courseware; } \\
\text { micro video: } \\
\text { import\&export, demo; } \\
\text { case: logical backup under } \\
\text { a MIS }\end{array}$ \\
\hline & 2.1 .3 & $\begin{array}{l}\text { Physical } \\
\text { Backup }\end{array}$ & point & understand & middle & $\begin{array}{l}\text { Courseware; } \\
\text { micro video: online \& } \\
\quad \text { offline backup, demo; } \\
\text { case: write a script of } \\
\text { online backup and offline } \\
\text { backup under a MIS }\end{array}$ \\
\hline & 2.2 & Recovery & range & & & self-test exercises \\
\hline & ....... & ............... & & & & \\
\hline
\end{tabular}

Making the micro video is the final stage of the preparation period according to the detail of composition of knowledge points. The playback time of each video is not more than 8 minute, which describe the knowledge points in finite time, so that the students will not feel tired about learning. The micro video can also be played on mobile devices, students can make use of fragmented time to learn these knowledge points. The video presents not only the PPT and operation demonstration, but also have more vivid demonstration of the flash to strengthen the points of knowledge, with some simple animation to illustrate the problem. These material including micro video, courseware, teaching 
material exercises are stored in the auxiliary learning software platform, which reflect truly the meaning of "flipped classroom".

Prearrangement Period. This stage is the most frequent interaction between teachers and students, the stage of knowledge learning are like wine fermentation process. The phase of the activity is shown in figure 1, Classified the learning content and knowledge points is the first step, which form different configuration of learning on the course, to meet the needs of the students in different levels. This teaching mode design three kinds of package configuration, to suit the varying degree student.

- Fundamental Configuration Package

The package includes the required knowledge points whose difficulty is easy and middle in the syllabus to master, for example theoretical knowledge of database system, paradigm, the relational database model and algorithm, SQL language, database backup and restore, etc., but does not include the difficult knowledge points in the syllabus, such as database modeling, query optimization.

Fitness: Most students did not learn the database related knowledge.

- Improvement Configuration Package

This package will relates to the knowledge of database application, including database management system learning (with Oracle database as an example), such as the Oracle database structure, the automatic and manual installation, maintenance of Oracle database, disaster recovery and other knowledge points. Students can master the knowledge of some commonly database management system through the learning of the package.

Fitness: The student who complete self-test exercises about basic knowledge of database in the preparation period, and get more than $80 \%$ exercises, this part of the students have learned the knowledge database system, have a certain understanding of the database.

- Elite Configuration Package

This type of package will lead the students directly into the database design aspects, such as management information system modeling, stored procedure, and query optimization.

Fitness: students who complete self-test exercises about the database of basic knowledge and application of database related knowledge in the preparation period, and correct rate more than $80 \%$. The students have self-study the knowledge of database, and proficiency in the use of a database management system. They are not only proficient in database theory knowledge, but also skilled in the use of database management system, database modeling, who need more experience and engineering case.

Student can choose the package according to their own actual situation, which will be registered by teacher. Then the teacher releases the study guide according to the package. Student can learn the knowledge points through complete self-check problem sets, micro video of the course, research the advance knowledge points on the basis of the mastered knowledge, or combine with the video and the teacher's lectures to learn knowledge. In the process of learning, the students can ask questions about the course in the software platform, the teacher answer the question timely and puts forward new problems to guide students to learn knowledge. After finishing all the knowledge points through the above loop iteration process, the prearrangement period is over.

Implementation Period. The implementation period is the stage that teacher test the teaching effect and students evaluate their learning stage. First, the teacher will formulate several topics on projects' requirements and background introduction. Then students are grouped under the guidance of teachers, a group of about $4 \sim 5$ people, each group choose a topic, given $2 \sim 3$ weeks to complete the selected topic. The group must commit the database design specification and PPT to show results. Students will learn to use the knowledge to the selected topic based on the technology they have mastered in the prearrangement period, complete the topic and display the results. The method can effectively exercise the student's ability of team cooperation. At last, teacher will check the result and evaluate the processing of the group, the result can be used as one of the final grade in this course. 


\section{Conclusion}

The course of the design and application of database has adopt the new teaching mode in our school for a year, a total of 400 students and 5 teachers participate in. Teachers and students have a strong interest in this new teaching mode, especially the following.

Establish the Student-centred Teaching Mode. Students have fully autonomous learning in the new teaching mode instead of accept the knowledge passively in the traditional classroom, they can choose learning package, time and schedule according to the situation of learning. Most of the work for teacher is making fun of the micro video, guide the classroom teaching activities, answer questions and check the student work. All teaching activities are carry out around "how to make students better master knowledge".

Teaching Method have a Variety of Forms. The teaching means in the new teaching mode has present the trend of diversification, and emerged in endlessly. Student can learn knowledge by micro online video, can ask questions and get answers online, can be organized to participate in the exercise of the project, can take the online test, even using their mobile devices to complete the homework, etc. The whole teaching process is organized, driven by engineering examples.

Convert Inside and Outside the Classroom. In the teaching process diagram, it is not difficult to find that extracurricular activity more than in-class activity. First of all, the teacher prepares a lesson is no longer the traditional books and lesson plans, instead of making video, select project cases, teaching process, which requires teachers to spend more time to find material in order to make better video, get more engineering applied projects. Secondly, the teacher mainly to solve the problem of engineering case in the classroom to guide the students to learn lessons, told the students "what to learn, how to learn", answer students' questions who encountered in the study of micro video, to evaluate student work and grades. Students can not only study by themselves according to the configuration package, but also make full use of their spare time to study. The final assessment results can be the mixture of a variety of ways, which reflect the students' learning situation. Such a "project-driven teaching Mode of the flipped classroom" loved by students greatly.

\section{Acknowledgements}

Project supported by the classroom teaching reform project of Zhejiang Higher Education (Grant No. $\operatorname{kg} 2013542)$

\section{References}

[1] Jonathan Bergmann, Aaron Sams. Flip Your Classroom: Reach Every Student in Every Class Every Day. International Society for Technology in Education press. 2012.7.15.

[2] M.L. Li, Y. Zhang, B.G. Ye etc., Decoding Massive Open Online Courses, Tsinghua university press, 2013.12.1, No 1.

[3] J. Yan, L.M. Gu: The Teaching Practice Based on project-driven method of "Database Technology" course. China Electric Power Education, 2014(08): pp.106-107.

[4] S.J. Fen. The Discussing of Case Teaching on "Advanced Database Technology" Course. The Chinese Journal of Ict in Education, 2013(7): pp.53-55.

[5] Y.L. Li, P.Y. Li: Internalization of Knowledge: the Cultivation of the Computational Thinking and Database Teaching. Journal of China university teaching, 2013(7): pp.33-35.

[6] Mason, G.S., T.R. Shuman and K.E. Cook, Comparing the Effectiveness of an Inverted Classroom to a Traditional Classroom in an Upper-Division Engineering Course. Education, IEEE Transactions on, 2013. 56(4): pp. 430-435. 
[7] Van Veen, B., Flipping Signal-Processing Instruction [SP Education]. Signal Processing Magazine, IEEE, 2013. 30(6): pp. 145-150.

[8] R.L.Luo: Teaching Practice of Database Application Development, in Educational and Information Technology (ICEIT), 2010 International Conference on. 2010.

[9] Information on

http://www.jxteacher.com/wyjy/column20374/131d4c12-859f-4356-bc15-6373ab060ef3.html.

[10] Information on http://www.jyb.cn/basc/jysw/201404/t20140409_577380.html.

[11] Information on http://www.icourse163.org/course/pku-21016\#/info 